- The Health and Social Care Bill will change the face of NHS primary care dentistry in England and Wales from April 2005. It marks the end of the NHS general dental services as they have been run since 1948 .

- This article explains what is in the various sections and clauses of the Bill, which include provisions for dental public health, new general dental services contracts, assistance and support, the abolition of the Dental Practice Board as well as patients' charges.

- The views of the Department of Health on the possible effects of the changes are also noted.

\title{
The Health and Social Care Bill
}

\author{
M. Watson $\mathrm{OBE}^{1}$
}

This Bill, which was published on 13th March 2002, has been described as 'paving the way for the biggest shake-up in NHS dentistry for over half a century". John Renshaw, Chairman of the British Dental Association's Executive Board called it a 'once in a generation opportunity to save NHS dentistry after decades of neglect by successive governments." He said the Association welcomed the Government's move to secure a strong NHS dental service with improved access for patients. But the BDA had serious concerns that unless NHS dentistry was properly resourced, the Bill's promised reforms would not be delivered. 'There is,' he said, 'an urgent need to make the NHS a good place to work for dentists and other dental professionals. Better funding and steps to make NHS dentistry an attractive career must go hand-in-hand with the measures proposed in the Bill.'

The Bill has passed through all its stages in the House of Commons and is now being debated in the House of Lords. It should receive the Royal Assent and become law around November. During the Committee stage, similar clauses to those applying to dentistry were added to introduce changes in the General Medical Services Contract.

The Bill will only apply to England and Wales, although Scotland and Northern Ireland could well bring in similar legislation following this summer's elections. It will be 'enabling' legislation, that is to say it will 'enable' the Secretary of State (in England) or the National Assembly of Wales, to implement different parts of the Act (as it will be then) at different times. The target for implementing the dental part of it is April 2005, with it being run in 'shadow' form (ie on paper rather than in reality) during 2004/05.

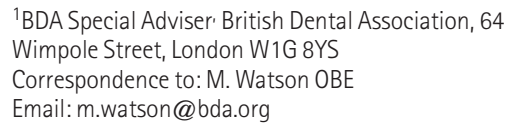

Received 15.04.03; Accepted 16.04.03

๑) British Dental Journal 2003; 195: 637-638
The Health and Social Care (Community Health and Standards) Bill, to give its full title, will set up NHS Foundation Trusts, which will not be subject to direction by the Secretary of State. Instead, an independent regulator will monitor their performance. They will be part of the NHS but will have greater financial and management freedoms including freedom to retain surpluses and to invest in delivery of new services, to flexibly manage and reward their staff and to access a wider range of options for capital funding. The Bill will also establish the Commission for Healthcare Audit and Inspection (CHAI), which will carry out reviews and investigations of healthcare provided by NHS bodies.

\section{PRIMARY DENTAL SERVICES}

Clause 166 of the Bill says primary care trusts* (PCTs) must secure the provision of primary dental care in their area to a 'reasonable' extent. The PCT may contract with local GDPs to provide these services or provide them through salaried services. This will be the first time that a health organisation has been given such a duty in respect to dental care. It becomes a 'must do' task, which cannot be ignored. PCTs will be judged on how well they carry out this responsibility. The Bill also puts salaried services on a statutory footing, whereas in the past they have been created through regulations.

\section{DENTAL PUBLIC HEALTH}

Section 167 of the Bill says that PCTs will also have a dental public health function to fulfil in terms set down in regulations. They can do this task themselves or work with other neighbouring PCTs, or delegate it to others. Public health functions could include oral health promotion, screening and surveys. How PCTs carry out this function will be for them to decide. GDPs could for example, undertake school screening or smoking cessation.

\section{GENERAL DENTAL SERVICES CONTRACTS} (CLAUSE 168)

As well as providing services themselves through salaried services, PCTs can fulfil their obligations via personal dental services and general dental services using 
contracts with practices. They will be known as General Dental Services Contracts and they will stipulate what services are to be provided and the remuneration under the contract.

The contracts will usually be NHS contracts where disputes are dealt with by the NHS. But there is provision for them to be legally binding contracts, where a court would decide on resolution of disputes.

The contract will lay down what services the dentist/practice must provide and the way in which they will provide them. PCTs are unlikely to have a free hand in setting up contracts, but there will probably be some central direction about what they should contain and a number of templates which can be used. It will be for the BDA to discuss these with the Department of Health over the next year.

PCTs will be able to contract with a single handed practitioner, a dental body corporate or with two or more people in partnership. In the latter case there will be two or more people at least one of whom should be a dentist but could include other health care professionals (professionals complementary to dentistry; PCDs) in the practice. Such an arrangement could well become more popular with groups of dentists forming themselves into corporate bodies when the rules allow. There would be nothing in the Bill, however, to prevent a PCT from negotiating individually with all the dentists in the practice, thus perpetuating the 'associate/principal' arrangement common today. A PCT might, however, be unwilling to do this with dentists who have no control over the premises and might not stay with the practice.

Under important transitional arrangements (Clause 160), which concern those dentists who are currently providing services in the GDS, the PCT can be compelled to enter into a general dental services (or other) contract with those dentists and the section provides that this should not be financially detrimental to the dentist. This is an important safeguard for GDPs and will require careful discussion over the coming year.

The health departments* can require the PCT to make certain payments under their contract. Before making these stipulations the health departments must consult any body seen to be representative of dentists and others affected by the Bill. These could include:

- Payments related to standards or levels of performance

- Payments by reference to a nationally agreed scheme

- Payments for individual practitioners

- Payments with conditions attached, and

- Making provision for any change not to be detrimental to practitioners.

This section is important for the BDA and we will need to investigate what it means in dentist-speak as opposed to legal-speak. It appears to imply that they are not being prescriptive about contracts and methods of remuneration; it could also introduce "quality and outcomes payments' as are in the proposed GMP contract; continuation of seniority payments, maternity allowances and so on; some sort of prior approval or clinical pathways. The 'no detriment' part appears vital. All of this also needs to be discussed over the next year.

A contract must also specify a number of other terms:

- How services are to be provided and standards to be achieved

- Who will perform the services

- To whom the services will be provided (the patients)

- How the contract can be varied, enforced and ended, and

- PCT's rights of entry and inspection.

This will be subject to negotiation between the BDA and health departments over the coming year.

\section{PERFORMERS LIST}

Clause 175 obliges a PCT to hold a "performers list' of all healthcare workers in their patch. At first it will probably apply to dentists and doctors only, but will in time also relate to registered PCDs. Regulations will cover the form and details of this list. Much of this will replicate the present GDS lists, which will replace the existing independent practitioner and salaried lists. Its inclusion is one consequence of the post-Shipman atmosphere. It does appear that, although a PCT will need to list those dentists currently working in their area, presence on a list does not guarantee a job within the PCT area. If a dentist works in more than one PCT area, however, it will only be necessary to appear on one PCT list.

\section{ASSISTANCE AND SUPPORT}

Clause 176 allows a PCT to provide assistance and support to anyone providing or proposing to provide primary dental and medical services. Assistance includes financial assistance and could include help with setting up in practice or for expansion, as well as providing help with practice management and IT. Although PCTs have been reluctant (and unable) to provide such assistance in the past, it could be a bonus of integrating with the NHS family and a way of accessing some of the additional funding which the NHS is enjoying.

\section{DENTAL PRACTICE BOARD OF ENGLAND AND WALES}

The DPB is abolished, says Clause 177 bluntly. But Clause 178 allows for the establishment of a Special Health Authority, which could carry out many of the current functions of the DPB on behalf of PCTs. A Special Health Authority is established by regulations rather than an Act of Parliament, as is the case with the DPB. It is also controlled by the Department of Health. So it is still likely that 'Eastbourne' and its staff will continue to exist, albeit with a different role.

\section{DENTAL CHARGES}

Clause 179 allows dental charges to be reformed to remove the link with the GDS fee scale. The Secretary of State will be free to devise a system, within existing rules concerning maximum charge and current exemptions. ${ }^{\dagger}$ As now regulations will allow the amount of the charge to be deducted from the amount due to practices. The BDA will need to talk with the Department on this issue. The thinking at present is that the charge might be paid per course of treatment but banded according to their complexity.

The Department of Health says that the Bill will "create a new legislative framework for the NHS to contract with dentists at a local level with flexibility for such contracts to take a variety of forms. ${ }^{2 \neq}$ The key benefit, they say, is in enabling the NHS locally, through PCTs, to make contracts which enable dentists to focus on prevention as well as treatment, addressing local oral health inequalities.

There should also be benefits to dentists, they add, through enabling them to work in larger groups than currently. The BDA also believes that the Bill could remove dentists from what a recent Audit Commission report ${ }^{3}$ described as 'the treadmill' of NHS dentistry today.

$$
\begin{aligned}
& \text { British Dental Association. Once in a generation } \\
& \text { opportunity to save NHS dentistry, say dentists. } \\
& \text { http://www.bda.org/advice/news.cfm?ContentID=762 } \\
& 2 \text { Department of Health. Full regulatory impact } \\
& \text { assessment, Health and Social Care Bill, annex D Para } \\
& \text { 8, } 2003 . \\
& 3 \quad \begin{array}{l}
\text { Audit Commission. Dentistry - Primary dental care } \\
\text { services in England and Wales. September } 2002 .
\end{array}
\end{aligned}
$$

